\title{
A LAICIDADE NO PENSAMENTO DE TRÊS MULHERES DO INÍCIO DO SÉCULO XX: MIRADAS FEMINISTAS SOBRE O TEMA NA AMÉRICA LATINA
}

\author{
AleXANdRa Padilha Bueno \\ AndReA BeZERRA Cordeiro \\ Universidade Federal do Paraná (UFPR), Curitiba, Paraná, Brasil
}

\begin{abstract}
ResUmo: Este artigo busca analisar os debates em torno da temática que envolve educação, Estado e Igreja, no contexto latino-americano, nas primeiras décadas do século XX, baseados nos discursos produzidos por três intelectuais que fomentaram uma discussão acerca da laicidade do ensino. São elas: a brasileira Maria Lacerda de Moura, a argentina Carolina Muzilli e a uruguaia Paulina Luisi. Para o desenvolvimento das análises foram utilizadas fontes de autoria das três intelectuais, produzidas em diferentes contextos, tais como: livros, periódicos e comunicações apresentadas em Congressos da época. As mulheres escolhidas estiveram à frente de iniciativas polêmicas e de repercussão nacional e internacional, relacionadas à educação, inserção e a emancipação das mulheres. O texto está dividido em três partes. Inicialmente, uma breve discussão do corpus documental e sobre as questões teóricas que ancoram as análises. Em seguida, discute-se a questão da laicidade por meio do contexto em que tais discussões surgiram, buscando compreender como a questão da laicidade do ensino estava vinculada a outras pautas. Na sequência, foi necessário lançar um olhar sobre as trajetórias individuais das intelectuais escolhidas de forma a refletir sobre as motivações que as levaram a difundir os discursos a favor da laicidade na educação.
\end{abstract}

Palavras-chave: Laicidade. História da educação. Feminismo século XX.

\section{INTRODUÇÃO}

As complexas relações entre educação, Estado, igreja e sociedade, no contexto latino-americano, nas primeiras décadas do século XX, serão aqui analisadas a partir da discussão da laicidade nos discursos produzidos por três intelectuais, unidas neste artigo por sua defesa à emancipação feminina. Tais mulheres fizeram circular ideias acerca do papel da laicidade do ensino para a efetivação da emancipação da mulher, desenvolvimento da sociedade e formação da infância. São elas: a brasileira Maria Lacerda de Moura', a argentina Carolina Muzilli e a uruguaia Paulina Louise.

As intelectuais serão estudadas "[...] a partir de suas práticas sociais, dos seus lugares de enunciação, das suas redes de sociabilidade, dos seus compromissos políticos com as elites ou com aqueles que defendem a subversão do poder" (VIEIRA, 2008, p. 78). 
Buscaremos também apontar a dimensão das "lutas de representação" (CHARTIER, 1991) que se faziam presentes nos debates em torno do tema da laicização da escola no início do século XX no Brasil e na América Latina, através de "estratégias simbólicas que determinam posições e relações e que constroem, para cada classe, grupo ou meio, um ser-percebido constitutivo de sua identidade" (CHARTIER, 1991, p. 183).

Para compor tal análise, foram utilizados documentos produzidos e publicados por Maria Lacerda de Moura, Carolina Muzilli e Paulina Louise durante as décadas de 1910 e 1920. As fontes escolhidas são de diferentes tipologias e fazem parte de vários acervos históricos, entre eles a Biblioteca Carlo Aldegheri (NELCA), que disponibilizou os livros de autoria de Maria Lacerda de Moura digitalizados, o acervo do Arquivo Nacional do Rio de Janeiro, no qual foram selecionadas algumas correspondências da mesma autora, arquivos de Edgart Leuenroth na Unicamp em São Paulo, o sítio da Hemeroteca Digital que possibilitou o acesso a artigos da imprensa periódica da época de autoria de Lacerda e também as fontes documentais que refutam as posições desta intelectual, que estão disponíveis em formato digital, além de acervos pessoais.

As intelectuais do Uruguai e Argentina, Paulina Louise e Carolina Muzilli, tiveram suas obras localizadas na Biblioteca Nacional do Uruguai e nos acervos da Biblioteca Luis Morchio, no Instituto Interamericano del Niño, la Niña y Adolescentes, no Uruguai, local onde também foram localizadas as fontes relativas aos três primeiros "Congresos Americanos del Niño (1906 a 1922)" mobilizadas para esta discussão. Perfazem, por tanto, o corpus documental desta análise: obras de autoria das intelectuais estudadas, artigos e entrevistas, correspondências, bem como teses e comunicações apresentadas por essas mulheres em congressos da infância.

Embora pertencentes a diferentes contextos e espaços sociais, defendo pautas que se entrecruzam, mas não são idênticas, as três reafirmarão a laicidade como ponto fulcral para o desenvolvimento intelectual, político e de cidadania da mulher. A forte presença dessa temática por vieses diversos é reveladora, pois, seja através das reivindicações especialmente focadas nas mulheres operárias de Carolina, a preocupação com o desenvolvimento intelectual da mulher de Maria Lacerda e as demandas de ordem médica e higiênica de Paulina, vislumbramos a centralidade da preocupação com a influência da religião sobre a mulher em seu desenvolvimento profissional, educacional e no governo de seu próprio corpo.

A possibilidade de cotejar os discursos dessas três mulheres latino-americanas do início do Séc. XX nos traz à reflexão a ideia de Touraine (2010) de que as mulheres insistem e insistiram historicamente em posicionarem-se no mundo não apenas pelo viés da denúncia às desigualdades e violências a que eram (e são) submetidas, mas que, coletivamente, impulsionaram rupturas com a "ordem cultural estabelecida que, ontem e hoje, permitiu que em números cada vez maiores as mulheres se considerem sujeitos" ( $p$. 89).

Portanto, neste sentido, o que veremos são os pensamentos de mulheres que refletirão, a partir de seu lugar no mundo, sobre a influência da religião na escola e nas políticas de Estado, sobre as mulheres e suas possibilidades de emancipação e afirmação como sujeitos da história. 
BUENO, A. P.; CORDEIRO, A. B.

ESCOLA, ESTADO, REPÚBLICA E LAICIDADE: BRASIL, URUGUAI E ARGENTINA NO CONTEXTO DO INÍCIO DO SÉCULO XX

Analisar as ideias acerca da laicidade escolar no discurso de três mulheres militantes e intelectuais em intensa atividade no início do século XX no Brasil, Uruguai e Argentina exige um retorno breve aos debates que possibilitaram a separação entre lgreja e Estado em uma América Latina de colonização fortemente marcada pela tradição cristã católica, cuja preponderância foi praticamente absoluta em se tratando do ensino e cuja influência era não apenas acatada mas festejada e desejada pelo Estado colonial.

Os debates pulsantes sobre a temática durante todo o século XX - e que ainda pulsam no século XXI - nos dão a dimensão do quanto a escola pública é território de disputa ideológica e de como a raiz do embate entre a presença ou ausência da religião neste território está profundamente cravada em solo latino americano, estando longe de ser ponto pacífico como princípio republicano e democrático.

$O$ fato de a religiosidade poder ser considerada parte constitutiva da identidade de uma nação (MUSCARÁ, 2010), em forte medida, justificou para muitos a necessidade de sua presença nos projetos educacionais das nações ao final do século XIX, no entanto serão as próprias bases da escola moderna e do projeto modernizador as responsáveis por parte da forte argumentação que apartaria a Igreja da escola pública e de outros espaços públicos onde antes imperava a influência da religiosidade cristã, sobretudo católica, em muitos países da América Latina.

Pineau (2008) ressalta o entrelaçamento irredutível entre modernidade e escola de massas, e, nesse sentido, o avanço das ideias de modernização e da influência positivista - de matriz preponderantemente francesa - sobre os projetos de governo nas nações americanas que se estruturavam, após suas lutas por independência e definição de territórios, será essencial no processo de laicização das nações americanas na sua busca por um lugar dentro do rol dos povos civilizados ou "do concerto das nações", nas palavras de Kuhlmann Jr. (2001). A construção de uma identidade sob os paradigmas republicanos liberais é parte da dinâmica de busca de espaço e de emancipação política, econômica e simbólica, que exigia um desvencilhamento do imaginário construído em torno da colonização, no qual a Igreja Católica teve forte papel. Nas palavras de Mignolo (2007), será a simbólica busca pela cicatrização da "ferida colonial" e seu legado.

Nesse contexto, a realização de encontros científicos e congressos especializados será uma das estratégias de afirmação das nações na difusão e inserção das ideias "progressistas", e o período entre finais do século XIX e início do XX será pleno destes eventos que se configuram como lugares estratégicos para os países propagandearem sua adesão aos avanços científicos e tecnológicos (PESAVENTO, 1997) e uma oportunidade de intercâmbio de ideias. E a formação de redes de contatos.

A América latina, em consonância com a Europa e América do Norte, será palco para uma profusão desses encontros com temas variados, entre eles os Congressos da Criança, fórum de encontro de intelectuais e filantropos envolvidos com a temática da infância em suas diversas faces (médica, educacional, jurídica, assistencial) no movimento de valorização estratégica da infância. Será no bojo desses congressos que encontraremos mais claramente a confluência das ideias de Maria Lacerda de Moura, Paulina Luisi e Carolina Muzilli, todas congressistas participantes em momentos das três 
primeiras edições dos Congresos Americanos del Niño, realizados na Argentina (1916), Uruguai (1919) e Brasil (1922).

Os movimentos pela laicização da sociedade perpassarão os púlpitos, as tribunas públicas, os congressos e eventos científicos, a imprensa e ganharão as ruas (MUSCARÁ, 2010, p. 349). Dividindo opiniões, mas obtendo de forma geral o triunfo legal da laicização dos espaços públicos, sem que isso se dê de maneira homogênea e total nos aspectos das práticas sociais ativas nesses espaços e nas representações delas. Há permanência e resistência de ideias e práticas de franca matriz cristã, como veremos adiante de maneira um pouco mais detalhada.

No Brasil, será pela via do Decreto no 914-A, de 23 de Outubro de 1890, submetido pelo Governo Provisório ao Congresso Constituinte, em seu artigo Art. 72, que serão estabelecidas as novas diretrizes republicanas que instituem a liberdade de culto, o casamento civil, a secularização dos cemitérios, a separação entre Igreja e Estado, e a laicização do ensino ministrado em estabelecimentos públicos. Tal decreto legitimava um rompimento entre Igreja e Estado oficializando pressupostos do pensamento liberal positivista em crescimento entre a intelectualidade brasileira desde meados do século XIX e refutando os posicionamentos da Igreja católica em sua perspectiva de ação junto ao Estado sobre a coisa pública. (GONÇALVES NETO, 2010, p. 201)

A força da legislação não deve ser minimizada, no entanto as resistências serão mantidas na forma dos usos dos espaços públicos como repartições, escolas e cemitérios, de onde os vestígios da religiosidade não serão facilmente apagados ${ }^{3}$ e ainda que os conteúdos religiosos tenham sido retirados oficialmente das escolas serão inúmeras as vias de manutenção da influência religiosa no ensino básico, percebida, sobretudo, no espaço e no tempo escolar ainda muito regrados pela mística religiosa, com as festividades do calendário cristão a permearem o calendário escolar de maneira incisiva, e também na abordagem dos próprios conteúdos escolares.

$\mathrm{Na}$ Argentina, a Ley 1420 estabeleceu as bases de um sistema nacional de ensino no ano de 1884. A estruturação do novo sistema nacional de educação pública será igualmente marcada por um projeto de governo e outro de nação fortemente referenciado no ideário positivista francês e na própria legislação educacional da França. Os objetivos declarados em seu artigo, primeiro, destacam "o desenvolvimento moral, intelectual e físico de todas as crianças entre seis e quatorze anos", desenvolvimento este a ser conquistado sob "os preceitos da higiene", conceito que marcará o caráter científico dos novos projetos e comporá com muita força "o novo ordenamento escolar proposto pela doutrina médico-higiênica" (ROCHA; GONDRA, 2002).

Conquanto a reforma da educação de 1884 tenha sido amplamente embasada em debates intelectuais e estivesse amparada em um movimento de difusão da escola de massas por todo o globo junto a nova lógica moderna da ideologia liberal, a premissa da laicidade encontrará também na Argentina fortes resistências, e o argumento de que a escola sem religiosidade formaria pessoas sem orientação moral será uma das chaves da organização da oposição católica à laicização da escola (MUSCARÁ, 2010, p.356).

No Uruguai, embora possamos falar em particularidades no processo de colonização e nas configurações políticas pós-independência no país, marcadas por grandes conflitos internos e pelo caudilhismo, em consonância com o restante da Améri- 
ca Latina, neste período, as escolas uruguaias estavam nas mãos de ordens religiosas católicas. Esse contexto será alterado a partir de um movimento político e intelectual liberal positivista que terá como expoente na busca pela implantação de uma escola pública o nome de José Varela, sendo que este, sob forte influência de intelectuais europeus, como Michelet, e norte americanos como Ira Mayhew, funda em 1868 a Sociedade de Amigos da Educação Popular (DIANA, 2014), organização que culminará com a instauração da Lei da Educação Comum de 1877, que instituirá a não obrigatoriedade do ensino religioso na escola primária.

A sociedade uruguaia já vinha experimentando um processo de secularização desde a laicização dos cemitérios em 1861 e, paulatinamente, entre o final do século XIX e início do século XX. Desse modo, a laicização do Estado se tornará um paradigma diferenciador e uma forte marca na identidade do país, pois, "paradoxalmente, a laicidade virou um conceito "sagrado" e por isso naturalizado ao ponto de ser sempre definido na sua origem mítica" (CAVANNA, 2010, p.178), essa origem mítica encontrará na "reforma valeriana" seu marco principal e na educação pública laica sua maior bandeira.

As lutas pelo território da escola pública entre projetos de um estado laico e de grupos religiosos podem ter sido abrandadas pela história, mas a necessidade de reiteração dos princípios de moralidade, por exemplo, presentes em discursos de educadores uruguaios do período inicial da lei da educação comum, sinaliza que, à população, ainda restavam dúvidas, reforçadas por vertentes religiosas e que a hegemonia de um a sociedade laica não se construiu sem resistências.

As modificações ocorridas ao longo desse transcurso, e o desejo pelo progresso, trouxeram novas demandas sociais. A esse contexto podemos acrescentar a chegada de trabalhadores imigrantes que, como trabalhadores do campo ou operários na ainda incipiente indústria, traziam consigo os princípios dos insurgentes movimentos sociais europeus. Tínhamos, portanto, uma sociedade permeada por ideias anarquistas, socialistas, anarco-sindicalistas, comunistas, feministas entre outras ${ }^{4}$. Um ambiente sociocultural propício para ascensão de inúmeros movimentos e associações que pretendiam, em ampla medida, mudanças significativas para a vida da população da época. Intelectuais e pensadores de diferentes nuances ideológicas engajaram-se em inúmeras frentes de lutas e fizeram de sua pena trincheira política. Maria Lacerda de Moura, Carolina Muzilli e Paulina Louise fizeram parte desse grupo, advogando em causas que ora se aproximam, ora se distanciam, mas, em ampla medida, foram movidas pelo desejo de mudança social.

\section{CAROLINA, PAULINA E MARIA: TRAJETÓRIAS DE ENGAJAMENTO E CRÍTICA SOCIAL}

\section{MARIA LACERDA DE MOURA}

Maria Lacerda de Moura, brasileira, mineira, nascida em Manhuaçu (MG), em 16 de maio de 1887, aos cinco anos, mudou-se para Barbacena (MG). Iniciou seu processo de escolarização na escola de freiras do asilo da cidade. Sobre a experiência com as freiras, Lacerda irá mencioná-la no conto Saudades da minha infância... Da minha infância querida, escrito para a Revista $O$ Malho (RJ). No texto, ela comentava sobre as agressões que sofria da família durante a infância e em seguida comenta: "depois de tantas surras, 
de tantos sermões, ainda na escola de irmãs de caridade me vinham falar do inferno. Que horror eu tive do inferno" (MOURA, 1935, p. 38). Na mesma cidade, ela cursou a Escola Normal e lecionou as disciplinas de pedagogia e higiene.

Seu pai era de origem humilde, exercia um cargo de oficial no cartório e envolveu-se com a doutrina espírita, o movimento anticlerical e maçônico de Minas Gerais - características que marcaram a formação de Maria Lacerda visto que, na vida adulta, participou de palestras em lojas maçônicas e escreveu obras de teor anticlerical. Casou-se com Carlos Ferreira de Moura. Lacerda não pode ter filhos e, por isso, adotou uma menina órfã e posteriormente seu sobrinho.

Ainda na primeira década do século XX, Maria Lacerda de Moura publicou dois livros importantes: Em torno da Educação, de 1918, e Renovação, de 1919. Segundo observam Schumaher e Brazil (2000), os livros foram expressões do otimismo que Lacerda tinha na educação feminina como instrumento transformador e na inclusão do povo no processo sociopolítico. Seu livro Renovação, por exemplo, teve ampla divulgação pela imprensa de Minas Gerais e de São Paulo, sendo que as críticas positivas que recebeu nos jornais paulistas the renderam convites para realização de conferências sobre a Emancipação Feminina em São Paulo e no Rio de Janeiro.

Foi a partir dessa repercussão positiva que Maria Lacerda de Moura tornou-se conhecida e passou a trocar correspondência com mulheres que estavam organizando a fundação de um movimento feminista nacional, entre elas, Bertha Júlia Maria Lutz. O encontro dessas duas mulheres culminou na fundação da Liga pela Emancipação Intelectual da Mulher (LEIM), associação feminista que foi substituída posteriormente pela Federação Brasileira e pelo Progresso Feminino, iniciativas das quais Maria Lacerda de Moura se afastaria rapidamente. Em carta anterior à fundação da LEIM, Lacerda alertava a Lutz sobre o empecilho que, de seu ponto de vista, representava a religião para a emancipação da mulher, enquanto a mulher patrícia estiver sob a tutela do padre impossível a sua emancipação. Portanto, é preciso um trabalho enérgico, perseverante, jeitoso para desvia-la aos poucos dessa escravidão mental [...] sabe bem que o clero não quer a nossa emancipação. A mulher é [toda] a sua arma de combate reacionário à ciência, do progresso. (MOURA, 1920, n.p.).

Lacerda irá se pronunciar inúmeras vezes sobre sua preocupação com a questão da laicidade de ensino como forma de preparar os homens e mulheres do seu tempo para uma emancipação intelectual e espiritual. Essa marca de seu pensamento fica evidenciada tanto no título de suas obras, como nos artigos que escreveu para imprensa e nas correspondências trocadas com seus pares intelectuais. Na carta escrita ao anarquista Fábio Luz em 1920, por exemplo, há uma crítica à formação da elite culta da época que segundo ela não era plenamente emancipada:

a meu ver é preciso preparar a elite intelectual - instruída, porém não educada e mui principalmente não emancipada. Oh! O mal que a Igreja romana faz! Demolir o dogma, fazer remexer o caráter, a coragem das convicções - educar os homens e mulheres para as conquistas do porvir - eis o que é preciso (MOURA, 1920, n.p.). 
Miriam Leite (1984) argumenta que o desprezo de Moura pelo clero e sua preocupação com as possíveis influências dele sobre a formação humana, se dava em função de que sua infância e adolescência se passaram em uma cidade do interior mineiro, na qual o clero católico mantinha-se na direção do ensino e das relações sociais e familiares. Para Maria Lacerda, a educação deveria ser integral, buscando o desenvolvimento pleno do indivíduo, potencializada a partir da higiene da mente e do corpo. Por isso, segundo ela, as consequências do domínio do clero católico na educação, poderiam levar a humanidade a uma espécie de cegueira seletiva pautada no dogma e no obscurantismo, contrárias a razão e a pedagogia científica.

Em 1921, Maria Lacerda mudou-se para São Paulo e ali passou a posicionar-se a favor do movimento anarco-sindicalista. Na cidade, ela foi diretora geral da Federação Internacional Feminina (FIF), um movimento associativista feminino criado por mulheres de Santos, São Paulo, e que tinha como objetivo a busca pelos direitos das mulheres que ali residiam. Embora tenha se posicionado a favor de tal movimento e de ter participado de inúmeras publicações voltadas aos operários e às mulheres operárias, Maria Lacerda de Moura recusou rótulos. Em entrevista ao periódico A Manhã em 1928 ela afirmava:

não sou feminista, já o declarei. Não sou comunista, não pertenço a nenhum partido político, não pontífico nem sirvo a nenhum rei, não exerço nenhum apostolado religioso ou social, não rumino em nenhum rebanho, acadêmico ou moralisterista, não bebo água da vida de nenhuma seita filosófico ou estilizado, clássico ou modernista. Livre de muletas. Livre de igrejas (MOURA, 1928, p 2).

Participou, em 1922, do Primeiro Congresso da Infância no Brasil. No evento, contribuiu com duas comunicações e uma tese, sendo que uma delas tinha como tema a Educação Laica. Do seu ponto de vista, a educação deveria respeitar a individualidade dos educandos, "a criança precisa saber pensar e julgar". De acordo com sua perspectiva:

a educação científica, racional se impõe. Saber o porquê das coisas, discutir, duvidar, é característica do espírito crítico da época. Procurar anular a influência jesuítica é dever da escola moderna. Não podemos mais admitir dogmas (MOURA, 1922, p. 385).

Para a autora, era fundamental que o ensino religioso fosse substituído pelas "ciências da vida', "hão se ser substituídos pela filosofia das religiões, pela ciência da vida. E virá então a cadeira estético-filosófica-religiosa em todas as escolas secundárias" (MOURA, 1922. p. 388).

Em 1923, Lacerda deixaria o magistério e passaria a publicar a revista Renascença na imprensa operária. Para ela, a questão da laicidade do ensino era crucial para o pleno desenvolvimento da emancipação feminina:

Metade do gênero humano está absolutamente sacrificada, impedindo o progresso das gerações vindouras. [...] E as existências femininas se deslizam e se extinguem entre costuras e bordados e limpeza de móveis e cuidados inconscientes com filhos não cuidados, vida sem ideal, sem noção do que possa ser a sociedade futura, sem visão da Beleza, sem um olhar dirigido em prol da ação para maior bem-estar (MOURA, 1924, p.564). 
Maria Lacerda permaneceu dois anos na diretoria da Federação e deixou o cargo em função de diferenças de posicionamento ideológico entre ela e outras mulheres que faziam parte da direção da associação. Utilizando de publicações para divulgar seu pensamento, Maria Lacerda causava polêmicas em vários periódicos do país (LEITE, 2005). Em 1924, publicaria $A$ mulher é degenerada?, tematizando questões relativas à sexualidade e à moral vigente sobre a mulher, obra que chegou à terceira edição (1925 e 1926) e teve uma tradução para o espanhol por uma editora Argentina (1925).

Escreveu, ainda, Lições de Pedagogia (1925), Religião do amor e da beleza (1926), De Amudsen a Del Prete (1928), Clero e Estado (1931), Civilização - Tronco de Escravos (1931), O problema da educação no pensamento e no idealismo de Ferrer, o mártir do ensino leigo (conferência), Amai e... não vos multipliqueis (1932) e Han Ryner e o amor plural (1933), Serviço militar obrigatório para a mulher? Recuso-me? (1933), Han Ryner e o amor no plural (1933), Clero e Fascismo, horda de embrutecedores (1933), Fascismo? filho dileto da Igreja e do Capital (1933) e O Silêncio (1944); também traduziu do espanhol para o português a obra $A$ liberdade sexual da mulher, de Julio Barcos, autor argentino que conheceu durante uma viagem que realizou para Buenos Aires em 1929. Durante o período de 1930 a 1936, ela participou ativamente como colaboradora da revista anarcoindividualista Estudios.

A contribuição intelectual de Maria Lacerda de Moura foi diversa e intensa. Ela posicionou-se de forma comprometida com causas nas quais acreditava e escreveu sobre temas controversos - família burguesa, maternidade compulsória, domínio sobre o corpo, divórcio, amor livre - criticando o Estado, o clero e o sistema representativo, na vigência de um regime de governo autoritário. Durante a Era Vargas (1934-1937), ela foi presa. Após sua soltura passou a viver no Rio de Janeiro, onde trabalhou na rádio Mayrink Veiga, realizando a leitura diária de horóscopo. Faleceu em 1945, com 58 anos.

\section{CAROLINA MUZILLI}

Em 1889 nasceu, em Buenos Aires, Carolina Muzilli, em uma família de classe média baixa, num bairro popular, avizinhado aos bairros operários pobres da cidade. Buenos Aires, no período da infância de Carolina, vivia um momento de crescente prestígio internacional e auto-confiança nacional, sendo esta motivada pelos índices econômicos que via de regra são tomados como indicadores de prosperidade, não obstante as mazelas que passam quem faz a roda girar para que tais números se mantenham. Apesar da imagem de prosperidade, Buenos Aires era habitada pela mesma ordem de problemas presentes em todas as cidades que se modernizavam: o crescimento da pobreza, da exploração do trabalhador e, sobretudo, das trabalhadoras e crianças.

Nessa ambiguidade, Carolina crescerá brincando nas ruas com crianças filhas da classe operária, pelas quais desenvolverá uma identidade e empatia que será marca de seu trabalho intelectual e político. Ela frequentará a Escuela Normal del Profesorado de Lenguas Vivas, onde, segundo Osvaldo Ferreras (1999), experimentará tanto o desprezo por parte de colegas e professoras em decorrência de sua postura questionadora, como desenvolverá relações que a aproximarão do movimento anarquista e feminista, em especial através da inspetora escolar Mercedes Gauna de Maltagliata e da feminista Mary 
Jav. Mais tarde, sua principal influência virá dos estudos acerca do trabalho feminino e infantil na Argentina desenvolvidos por Gabriela de Laperrière de Coni, através da qual ingressará, em 1907, no Partido Socialista. (FERRERAS, 1999, p. 267)

Carolina seguirá seus estudos de maneira autodidata, tendo como principais veículos para a sua divulgação os jornais La Vanguardia (órgão oficial do Partido socialista) e seu próprio jornal, a Tribuna Feminina, ao qual editava e custeava com o trabalho de costureira doméstica, fonte de seu precário sustento.

A estratégia dos trabalhos de Muzilli - que, a exemplo dos de Gabriela de Lapierre Coni, se concentrarão na denúncia da exploração da mulher e criança trabalhadora e nas más condições de vida da classe operária argentina - foi trazer a lume tais debates usando, além da retórica contundente, dados estatísticos sobre as condições dos trabalhadores e trabalhadoras. A estatística foi uma ferramenta fundamental por trazer, de maneira mais crua e sem "sacrificar las ideas a las flores de trapo de la retórica" (MUZILLI, 1919, p.15), as informações coletadas em fábricas, oficinas, lavanderias, fazendas, cortiços e nas ruas das cidades. Esse exercício de racionalidade, bem ao gosto das tendências cientificistas, é empreendido conscientemente por Muzilli, para dar maior substância às suas palestras. "La obra de los escritores que se dedican a cuestiones sociales ha de ser, entonces, de precisión, para ser seria e conducente" diz no artigo La estadística Social (1919, p. 13-18).

Carolina participará ativamente do Centro Femenino Socialista, junto a socialistas feministas importantes no período como Raquel Caamaño, Gabriela de L. de Coni, as médicas Julieta Lanteri Renshaw, Cecilia Grierson, Elvira Rawson de Dellepiane e Alicia Moreau de Justo, e a poeta Alfonsina Storni. Nesse grupo se produzirá a ideia dos Congresos Americanos del Niño, durante o Primer Congreso Femenino Internacional, convocado pela Asociación de Universitarias Argentinas, socialista e feminista, evento propositalmente marcado em data coincidente (entre 18 e 23 de maio de 1910) com o Primer Congreso Patriótico de Señoras en América del Sur, organizado pelo Conselho Nacional de Mulheres, grupo tradicional católico e bem relacionado como o establishment.

Enquanto no Congresso Feminino se discutia a ampliação da igualdade civil e dos direitos políticos das mulheres, além de políticas públicas de proteção, saúde e educação à mulher e à criança, no Congresso Patriótico, eram debatidas contribuições femininas à pátria dentro dos moldes aceitos pela política patriarcal vigente, destacando-se a atuação da mulher enquanto criatura ponderada e maternal, bem como a defesa da interferência de instituições religiosas e privadas na assistência à infância. No decorrer da história dos movimentos femininos, na Argentina, a rivalidade das demandas e posições entre os grupos conservadores católicos e as feministas socialistas reaparecerá repetidas vezes, principalmente, pelo viés da disputa entre a filantropia e as políticas públicas de assistência à mulher e à criança e marcadamente nos debates sobre a laicidade na educação e na assistência social.

O laicismo era uma das premissas fundantes do socialismo argentino (FERRERAS, 1999, p. 285), e Carolina o abordará em seus trabalhos através da forte crítica à influência da religião na educação das mulheres e, principalmente, na denúncia dos prejuízos trazidos pela ideia de "caridade cristã" à sociedade e à emancipação operária, sobretudo da mulher trabalhadora. 
Em seu estudo Aspectos do trabalho feminino (1919), Carolina Muzilli discorre sobre o que considera uma hipocrisia das classes abastadas e das ordens religiosas, tomando como exemplo as celebrações do "Dia da menina Trabalhadora", no qual se realizavam coletas de doações para menores empregadas nos ateliês montados em orfanatos e outras instituições religiosas, onde produziam, sobretudo, finas roupas, chapéus e acessórios, consumidos pelas mulheres de alta sociedade:

Para descrever a situação das trabalhadoras exploradas pela religião e em nome dela só nos basta mencionar um dia: "O Dia da Menina Trabalhadora" [...] lindas damas e elegantes meninas com sorrisos estudados [...] invocam esmolas dos passantes para aliviar a situação das trabalhadoras exploradas nos ateliês de todo monastério que existe [...] onde até hoje nunca pode entrar a inspeção oficial - e já que estas meninas não tem um santo especial que as proteja contra os salários de fome a que as sujeitam em nome da religião as "irmãs" desta ou daquela ordem, lá estão as damas, que em troca da barateza do trabalho de uma menina tiveram a ideia de criar "o dia da menina trabalhadora" (MUZILLI, 1919, p.59, tradução nossa).

Para Muzilli (1919), nenhuma obra social deveria ser realizada sob a ideia da caridade cristã, que, para ela, se constituía em um "passatempo ou esporte praticado para humilhar mais ainda àqueles cuja desgraça levava a serem dominados" $(1919$, p.90) e que não tinha por propósito a igualdade social, mas a manutenção das desigualdades. Em outras palavras:

A Caridade! Que degradante é tudo que se escuda sob o degradante manto da caridade. Com ela se estabelece - uma vez que humilha aniquilando a vontade do indivíduo - entre o que lhe concede e o que a recebe uma inferioridade deprimente (MUZILLI, 1919, p.214, tradução nossa).

Em contrapartida, consonante às propostas socialistas, Carolina propunha a laicidade de fato, tanto na educação quanto nas obras de assistência social, na perspectiva de que o que necessitavam os pobres era de solidariedade e, sobretudo, de justiça social, a ser conquistada pela organização da classe trabalhadora e sua pressão sobre o estado.

Outra importante frente de militância de Carolina Muzilli estava na educação das mulheres. Muzilli, como "feminista maternalista", acreditava que o potencial intelectual da mulher era sacrificado por uma educação insuficiente para sua atuação em diferentes espaços da sociedade e, sobretudo, em sua missão de educar as crianças. Pois:

Há quem defenda que é obra de mau gosto educar a mulher fora de toda sujeição religiosa...Mal gosto combater uma tendência negativa que há mantido os homens durante séculos na mais espantosa abjeção, anulando a vontade, a independência, a personalidade! (MUZILLI, 1919, p. 222, tradução nossa).

Para Carolina, só a boa educação, laica, democrática e racional poderia "mostrar os caminhos da verdade e da justiça", levando à "conquista da beleza moral e material, 
destinada a estabelecer sobre bases sólidas o paraíso na terra, onde trabalhamos e sofremos" (1919, p. 223).

Carolina Muzilli morreu em 1917, de tuberculose, em decorrência das más condições de trabalho como costureira e de sua exposição às condições insalubres que pesquisava e denunciava como Fiscal do Trabalho. Os trechos de sua obra citados acima foram encontrados em um livro póstumo intitulado "Por la salud de la raza", dedicado a publicizar diversos artigos de Carolina que denunciavam a exploração da trabalhadora e da criança argentina. O exemplar que acessamos foi uma doação à Biblioteca Nacional do Uruguai pela família da feminista e ativista uruguaia Paulina Louise e que pertencia à biblioteca pessoal dessa médica ginecologista, também socialista e envolvida na proteção à infância, o que reitera a circulação de materiais e de ideias acerca do feminismo e debates sobre a infância entre os países da américa e américa latina

\section{PAULINA LUISI}

Paulina Luisi nasceu na Argentina, em 1875, e mudou-se para o Uruguai ainda muito pequena com sua família. Seus pais, Maria Teresa Janicki e Angel Luisi Pisano, eram imigrantes europeus, trabalhadores e educadores de pensamento bastante liberal, o que marca a trajetória dos oito filhos, que foram estimulados a estudar tendo alguma de suas moças optado por carreiras acadêmicas: Paulina formou-se como a primeira médica na Faculdade de Medicina do Uruguai em 1908, Luisa tornou-se poeta e pedagoga, Clotilde tornou-se a primeira advogada a se formar na Universidade da República e Inês também foi médica com sólida carreira.

Paulina, assim como sua mãe e irmãs, era uma sufragista, militante feminista e defensora da laicidade como princípio democrático. Sendo ginecologista e envolvida com a causa da profilaxia das doenças venéreas como forma de cuidado para com a saúde de mulheres e crianças, ela criticará com vigor a religiosidade e sua interferência sobre a educação sexual.

O texto Enseñanza Sexual, de Luisi, foi apresentado pela primeira vez no Primer Congreso Americano del Niño (1916-Argentina), na sequência publicado em forma de livreto no Uruguai em 1916 e será reapresentado no Terceiro Congresso Americano da Criança. Em sua essência, esse texto tece críticas às "teses obscurantistas" em torno do tema e recomenda que a escola se encarregue de uma instrução sexual, científica, clara, moral e sem dogmas. Ela acreditava que a criança, devidamente instruída na escola, seria agente de educação da comunidade. Segundo ela, a "corrente inversa" das crianças ensinando a seus pais sobre os princípios da instrução sexual promoveria uma indireta, salutar e necessária expansão da escola e das condições de saúde e bem-estar do povo (LUISI, 1916, p.23). Afirmou Paulina Luise, no Primer Congreso Americano del Niño (1916), que:

Disse Mme. Kergomard: $A$ educação sexual é ainda, no século XX, um espantalho a trinta milhões de francesas, pelo menos. O que poderia ser dito ser dito da mulher latino-americana, agarrando-se a preconceitos, com sua mente obscurecida pelo fanatismo, rendida cortesã das tradições sociais, puritana incorrigível, mas não impecável? É sobretudo nesta mentalidade das gentes, na ignorância do grande 
conceito da educação, onde está a barreira que impede que chegue a porto seguro o navio carregado com todos os tesouros da nova ciência. (LUISI, 1916, p.12).

Para ela, "nos países americanos o espírito religioso está profundamente arraigado no povo, entre as entre as mulheres particularmente" (LUISI, 1916, p.13), desta forma a religião seria um grande entrave ao progresso da ciência, da educação e do desenvolvimento. Em seus trabalhos, Luisi trará críticas diretas ao preconceito e ignorância impostos pelo excesso de dogmas em torno da temática da educação sexual, alimentados, segundo ela, pela religiosidade e pelo preconceito.

Luisi não temia abordar questões polêmicas como religiosidade e educação sexual e inclusive gostava de trazer os temas juntos. Em seus trabalhos, ela se lembrará dos embates no Uruguai na ocasião da aprovação da laicização da escola, traçando entre os dois temas interessantes e paralelos. Ela sublinhará que muitos pais resistiram e retiraram seus filhos da escola pública quando esta se tornou laica, matriculando-os em escolas particulares católicas, mas que em pouco tempo o impacto da mudança foi absorvido e as escolas públicas voltaram a estar cheias (LUISI, 1916). Para Luisi, o mesmo tipo de reação iria ocorrer quando da introdução da instrução sexual na escola, pois "seria o suficiente estabelecer que a instrução sexual fosse facultativa a critério dos pais; as primeiras violências acabariam vencidas e o ensino viria pouco a pouco para todos".

Essa visão otimista de Luisi quanto à aceitação da escola laica e da educação sexual encontrava poucos ecos no período, ao menos é o que nos mostram as fontes dos Congressos da Criança, em que ambos os temas causarão desconforto. Um dos recursos mais utilizados na tentativa de equalizar a polêmica estará no clamor à ideia de moral e de educação moral que aparecerá como uma alternativa possível "à retirada de Deus" das salas de aula.

\section{CONSIDERAÇÕES FINAIS}

Do ponto de vista da análise histórica, o processo de laicização da escola é para a história da educação um excelente observatório de lutas de representação. Nele, percebemos como mudanças, tais como a retirada do ensino religioso da escola pública, são embebidas de permanências, representadas aqui pela ideia da difusão, no projeto laico de educação, da moralidade em um substitutivo à ideia de Deus.

A inserção da moral nas propostas de ensino da escola republicana se constituirá não apenas em uma das premissas de um almejado projeto moderno de escola e de nação, mas também surgirá como uma contra mola à difusão do potencial perigo à formação moral dos cidadãos numa escola sem religião propagada pela Igreja em reação à laicidade escolar.

Aos alertas quanto aos perigos de uma educação sem moral porque sem Deus, se unirá a premissa da equiparação da laicidade com o ateísmo (GONÇALVES NETO, 2010; MUSCARÁ, 2010), a aproximação forçada desses conceitos povoará os debates conservadores no Brasil e na Argentina com possíveis e prováveis repercussões na opinião pública. 
Um exemplo dessa posição, que, segundo a pesquisa de Vidal (2003), encontraria respaldo na Igreja e em boa parte da opinião popular, encontra-se no trabalho da brasileira Maria da Glória Almeida, que, em 1922, afirmou no $3^{\circ}$ Congresso Americano da Criança:

A educação moral deve ser baseada em princípios religiosos que penetrem o coração da criança; os modernos educadores, mesmo os ateus, vêm reconhecendo as lacunas funestas que o ensino leigo deixa na alma do povo (1924, p. 450).

Mateus Legnani ilustra o mesmo princípio ao debater a "higiene" como saber escolar no Segundo Congreso americano del Niño (1919) e dirá:

O que eu busco senhores congressistas, é que já que lançamos Deus para fora da escola, não se permita que em seu lugar se instale o culto à vida, o culto à saúde sem que se explique ante às rápidas imaginações infantis que esse ideal é a vida e saúde da Humanidade [...] que os professores aprofundem o estudo da Higiene, desde o ponto de vista da Moral (LEGNANI, 1919).

Colocar a moral no espaço deixado pela retirada (ainda que parcial) da religiosidade da escola parece ter sido uma preocupação que acabará por perpetuar na escola uma série de princípios normatizantes que ombrearão com vários princípios religiosos, numa tensão que não se dissolverá mesmo na atualidade.

Carolina Muzzili, Maria Lacerda de Moura e Paulina Luisi não estavam alheias à lacuna deixada pela saída da religiosidade na escola, suas propostas por preenchê-la perpassam também a ideia de moralidade, mas uma moralidade que extrapolava o moralismo e reverberava as premências de seus contextos: Carolina pelo viés da moralização das relações de trabalho e valorização da classe operária, Paulina no pleito pela expansão da Educação Sexual como forma de dar chances de uma vida sadia e feliz à juventude e Maria Lacerda de Moura na ânsia de emancipação intelectual de homens e mulheres através de uma moralidade baseada na ética, na estética e na igualdade.

Artigo recebido em: 30/01/2019

Aprovado para publicação em: 08/03/2019

\section{THE LAITY IN THE THINKING OF THREE WOMEN OF THE EARLY TWENTIETH CENTURY: FEMINIST VIEWS ON THE THEME IN LATIN AMERICA}

ABSTRACT: This article seeks to analyze the debates around the theme of education, State and Church, in the Latin American context, in the first decades of the twentieth century, based on the discourses produced by three intellectuals who fomented a discussion about the secularity of teaching. They are: the Brazilian Maria Lacerda de Moura, the Argentine Carolina Muzilli and the Uruguayan Paulina Luisi. For the development of the analyzes are used sources of authorship of the three intellectuals, produced in different contexts, such as: books, periodicals and communications presented in Congresses of the time. The women chosen were at the forefront of controversial initiatives and national and international repercussions related to the education, insertion and 
emancipation of women. The text is divided into three parts. Initially, a brief discussion of the documentary corpus and on the theoretical issues that anchor the analyzes. Next, the question of secularity is discussed through the context in which such discussions arose, seeking to understand how the issue of secular teaching was linked to other demands. In the sequence, it was necessary to look at the individual trajectories of the chosen intellectuals in order to reflect on the motivations that led them to spread the discourses in favor of secularity in education.

KEYWORDS: Secularism. History of education. 20th century feminism.

\section{LA LAICIDAD EN EL PENSAMIENTO DE TRES MUJERES DEL INICIO DEL SIGLO XX: MIRADAS FEMENINAS SOBRE EL TEMA EN AMÉRICA LATINA}

RESUMEN: Este artículo busca analizar los debates en torno al tema de la educación, el Estado y la Iglesia, en el contexto latinoamericano, en las primeras décadas del siglo XX, a partir de los discursos producidos por tres intelectuales que fomentaron una discusión sobre la secularidad de la enseñanza. Son: la brasileña María Lacerda de Moura, la argentina Carolina Muzilli y la uruguaya Paulina Luisi. Para el desarrollo de los análisis se utilizan fuentes de autoría de los tres intelectuales, producidos en diferentes contextos, tales como: libros, publicaciones periódicas y comunicaciones presentadas en los Congresos de la época. Las mujeres elegidas estuvieron a la vanguardia de las iniciativas controvertidas y las repercusiones nacionales e internacionales relacionadas con la educación, la inserción y la emancipación de las mujeres. El texto se divide en tres partes. Inicialmente, una breve discusión del corpus documental y sobre las cuestiones teóricas que anclan los análisis. A continuación, la cuestión de la secularidad se discute a través del contexto en el cual surgieron tales discusiones, buscando comprender cómo el tema de la enseñanza secular estaba vinculado a otras demandas. En la secuencia, fue necesario observar las trayectorias individuales de los intelectuales elegidos para reflexionar sobre las motivaciones que los llevaron a difundir los discursos a favor de la secularidad en la educación.

PALABRAS CLAVE: Laicidad. Historia de la educación. Feminismo siglo XX.

NOTAS

1) Conquanto Maria Lacerda de Moura, ao longo de sua trajetória em defesa pela emancipação feminina tenha recusado a alcunha de feminista, a intelectual aproximou-se do movimento feminista no início da década de 1920, participou ativamente da criação da Liga pela Emancipação Intelectual da Mulher (LEIM) no Rio de Janeiro, iniciativa ligada ao grupo feminista liderado por Bertha Lutz e também da Federação Feminina Internacional em São Paulo. Por isso, neste artigo, optamos por tratá-la como feminista.

2) Para maior aprofundamento no conceito de secularização, sugerimos a leitura da abordagem weberiana sobre o tema, empreendida por PIERUCCI (1998) na qual discute o processo de secularização baseado na macroracionalização ocidental na modernidade, envolvendo primordialmente a esfera jurídica e política, com a progressiva separação da religião do Estado. 
BUENO, A. P.; CORDEIRO, A. B.

3) Leite (2009) analisará a resistência dos modelos religiosos e sua permanência nos aparatos públicos no estudo Estado, Religião e a Presença de Símbolos Religiosos em Órgãos Públicos: um estudo dos casos Van Orden e McCreary County julgados pela Suprema Corte dos EUA. In: LEITE, Fábio Carvalho (Org.). Cadernos de Direito Constitucional. Rio de Janeiro: Departamento de Direito da PUC, 2009.

4) $\mathrm{O}$ desejo pela igualdade entre os sexos presente nos feminismos de diversas matizes, tempos e espaços sociais, deriva de uma tradição democrática e utópica da Modernidade. Conforme aponta Fraise (1989), desde o fechamento dos salões femininos em 1783, até a cidadania masculina assinalada no documento Declaração dos direitos dos homens e cidadãos, as mulheres não foram convidadas a debater assuntos relativos a coisa pública. Como menciona Touraine (2010) os temas igualdade e diferença, marcaram os debates em torno da história dos movimentos feministas e definiram, em ampla medida, parte da subjetividade feminina ao longo da Modernidade.

\section{REFERÊNCIAS}

BRASIL. Decreto no 914-A, de 23 de outubro de 1890. Coleção de Leis do Brasil - 1890, Página 3010 Vol. Fasc.X (Publicação Original). Disponível em: http://www2.camara.leg.br/legin/fed/decret/1824-1899/decreto-914-a-23-outubro1890-517812-norma-pe.html. Acesso: 30 maio 2018.

CARTA Manuscrita de Maria Lacerda de Moura à Bertha Lutz. São Paulo, SP, 21 de outubro de 1920 (Fundo Federação Brasileira pelo Progresso Feminino - Arquivo Nacional - RJ).

CARTA Manuscrita de Maria Lacerda Dias Moura ao Fabio Luz. Barbacena, 18 de novembro de 1920 (Fundo Fabio Luz - Arquivo Nacional - RJ).

CAVANNA, F. J. História do conceito de laicidade no Uruguai: do batllismo à doutrina da segurança nacional (1903-1972). 2003. 197 f. Tese (Doutorado em História) - Faculdade de História da UFPR, Universidade Federal Do Paraná, Paraná, 2003.

CHARTIER, R O mundo como representação. Estudos Avançados: Instituto de Estudos Avançados, São Paulo, v. 5, n. 11, 1991.

DIANA, E. de A. Educação e participação política em José Pedro Varela: a reforma vareliana como instrumento de democracia e progresso no Uruguai (1864-1879). In: ENCONTRO INTERNACIONAL DA ANPHLAC, 11., 2014, Niterói, Rio de Janeiro. Anais... Rio de Janeiro, 2014.

GONÇALVES NETO, W. A secularização da sociedade brasileira: tensões e conflitos em Minas Gerais nos primórdios da república. In: CARVALHO, C. H.; GONÇALVES NETO, W. (Org.). Estado, igreja e educação: o mundo ibero-americano nos séculos XIX e XX. Campinas: Alínea, 2010. p. 337-372. 
FERRERA, N. O. Carolina Muzilli ou a costureira que não deu o "mau passo". Cadernos Pagu, Campinas, São Paulo, n. 13, p. 253-292, maio 2015. Disponível em: https://periodicos.sbu.unicamp.br/ojs/index.php/cadpagu/article/view/8635329. Acesso em: 30 maio 2018.

KUHLMANN JR., M. As grandes festas didáticas: a educação brasileira e as exposições internacionais (1862-1922). Bragança Paulista: Editora da UniUniversidade São Francisco, 2001.

LEITE, M. L. M. Outra face do feminismo: Maria Lacerda de Moura. São Paulo: Ática, 1984.

LEITE, F. C.Estado, Religião e a Presença de Símbolos Religiosos em Órgãos Públicos: um estudo dos casos Van Orden e McCreary County julgados pela Suprema Corte dos EUA. In: LEITE, F. C. (Org.). Cadernos de Direito Constitucional. Rio de Janeiro: Departamento de Direito da PUC, 2009.

LUISI, Paulina. Enseñanza Sexual. I. Congreso Americano del Niño. Buenos Aires, 1916, Montevideo, Imp. El Siglo llustrado, 1916, s.p.

LEGNANI, Mateo. Recetas de higiene. II. Congreso Americano del Niño. Sección de Higiene y Asistência, carpeta 2, Tomo 6, Trabajos Inéditos, 1919, s.p.

MOURA, M. L. Conferência: A emancipação intelectual da mulher. Fonfon. Rio de Janeiro, 08 de janeiro de 1921, p. 24.

MOURA, M. L. Saudades da minha infância... Da minha infância querida. O Malho. Rio de Janeiro, 1935, p. 38.

MOURA, M. L. Educação Laica. Primeiro Congresso de Proteção à Infância. Realizado em 27 de agosto a 5 de setembro de 1922. Theses oficiais, memórias e conclusões. Rio de Janeiro, 1925. Coleção de Leis Provinciaes de Mato Grosso (MT) 1835 a 1912. Disponível em:

http://memoria.bn.br/DocReader/DocReader.aspx?bib=800058\&PagFis=3746\&Pesq=ma ria\%20lacerda\%20de\%20moura.

MIGNOLO, W. La idea de América latina: la herida colonial y la opción decolonial. Barcelona: Gedisa, 2007.

MUSCARÁ, F. Estado, Iglesia y educación em Argentina (ss.XIX y XX). In: CARVALHO, Carlos H.; GONÇALVES NETO, W. (Org.). Estado, igreja e educação: o mundo iberoamericano nos séculos XIX e XX. Campinas: Alínea, 2010. p. 337-372.

MUZILLI, C. Por la salud de la raza. Virtus Editora. Buenos Aires, 1919. 
BUENO, A. P.; CORDEIRO, A. B.

PESAVENTO, S. J. Nós e os outros: as exposições universais e o imaginário europeu sobre a América. In: BESSONI, T. M. T.; QUEIROZ, T. A. P. de (Org.). América Latina: imagens, imaginação e imaginário. Rio de Janeiro: Expressão e Cultura; São Paulo: EDUSP, 1997. p. 557-567.

PIERUCCI, A. F. Secularização em Max Weber: Da contemporânea serventia de voltarmos a acessar aquele velho sentido. Revista Brasileira de Ciências Sociais, São Paulo, v. 13, n. 37, p. 43-73, jun. 1998. http://dx.doi.org/10.1590/S0102-69091998000200003.

PINEAU, P. Como a noite engendra o dia e o dia engendra a noite revisando o vínculo da produção mútua entre escola e Modernidade. Pro-Posições, Campinas, v. 19, n. 3, p. 83104, Dec. 2008. Disponível em:

$<$ http://www.scielo.br/scielo.php?script=sci_arttext\&pid=S010373072008000300005\&ln $\mathrm{g}=\mathrm{en} \& \mathrm{nrm}=\mathrm{iso}>$. Access on: 21 maio 2018.

ROCHA, H. H. P.; GONDRA, J. G. A escola e a produção de sujeitos

higienizados. Perspectiva, Florianópolis, v. 20, n. 2, p. 493-512, jan. 2002. Disponível em: https://periodicos.ufsc.br/index.php/perspectiva/article/view/10449. Acesso em: 30 maio 2018.

SHUMAHER, S.; BRAZIL, E. V. (Org.). Dicionário de mulheres do Brasil: de 1500 até a atualidade. Rio de Janeiro: Jorge Zahar, 2000.

TOURAINE, A. O mundo das mulheres. 2. ed. Petrópolis: Vozes, 2010.

VIDAL, D. G. Educação Sexual: produção de identidades de gênero na década de 1930. In: SOUSA, Cynthia Perereira de (Org.). História da Educação: processos, práticas e saberes. São Paulo: Escrituras Editora, 1998.

VIEIRA, C. E. Intelligentsia e intelectuais: sentidos, conceitos e possibilidades para a História Intelectual. Revista Brasileira de História da Educação, Brasil, v. 1, p. 63-85, 2008.

\footnotetext{
Alexandra Padilha Bueno: Doutoranda em Educação pela Universidade Federal do Paraná (UFPR), Mestra em Educação pela Universidade Federal do Paraná (UFPR) e Graduada em Pedagogia pela Universidade Federal do Paraná (UFPR), foi coordenadora de alfabetização do ensino fundamental do Núcleo de anos iniciais da Secretaria da Educação do Município de Araucária (Gestão 2009-2012). É professora da Educação Básica no Município de Araucária, atuando principalmente com turmas do ciclo de alfabetização.

OrCID: http://orcid.org/0000-0002-0351-0060

E-mail: alexandrap.bueno@yahoo.com.br
} 
Andrea Bezerra Cordeiro: Doutora em Educação pela Universidade Federal do Paraná na linha de História e Historiografia da Educação (2015). Possui mestrado em Educação pela Universidade Federal do Paraná (2005) e é graduada em Pedagogia pela Universidade Federal do Paraná (2000). Professora Adjunta no Departamento de Planejamento e Administração Escolar do Setor de Educação da Universidade Federal do Paraná.

ORCID: https://orcid.org/0000-0002-6963-5261

E-mail: andreacordeiroufpr@smail.com

Este periódico utiliza a licença Creative Commons Attribution 3.0, para periódicos de acesso aberto (Open Archives Iniciative - OAI). 